\title{
Evoked cortical response during vigilance
}

ROBERT T. WILKINSON ${ }^{1}$, HENRY C. MORLOCK ${ }^{2}$ AND HAROLD L. WILLIAMS 3

WALTER REED ARMY INSTITUTE OF RESEARCH

In a conventional vigilance situation a relationship has been found between the averaged evoked cortical response to the vigilance stimuli and the $S s^{\prime}$ ability to detect occasional, slight changes in these stimuli. The pattern of change in the evoked response that accompanied failures of detection suggested lowered arousal rather than distracted attention as the cause.

The amplitude of the evoked cortical response (ECR) in man has been found to vary with the attentional state of the S towards the stimulus concerned (Larsson, 1960; Garcia-Austt et al, 1961). Similar attentional states have been thought to play an important part in deciding the degree to which performance declines during prolonged vigilance (Mackworth, 1950; Broadbent, 1958). This study has attempted to bring together these two covariates of attention by recording the ECRs to the repetitive, 2-sec. click stimuli of a 2-hr. vigilance task and correlating these patterns with performance (detection of an occasional click slightly quieter than the rest).

\section{Method}

Five enlisted men and three college undergraduates carried out a vigilance test once, following a practice session. The S sat in an electrically shielded cubicle and listened to clicks from a loudspeaker $1 \mathrm{ft}$ behind his head. Clicks occurred every $2 \mathrm{sec}$. for the duration of the test, $2 \mathrm{hr}$. During this period 16 softer clicks, attenuated by about $1-2 \mathrm{db}$, were randomly substituted for the regular ones. Four such "signals" occurred within each $1 / 2 \mathrm{hr}$. of the test. The $\mathrm{S}$ was instructed to report these events by pressing a key.

The clicks, about $40 \mathrm{db}$ above the S's threshold, were produced by amplifying the output pulses of a Tektronix, Type 161 Pulse Generator and feeding them to an 8-in cone speaker behind the $S$. Scalp potentials were recorded between silver disc electrodes placed on the vertex and on the right mastoid process. Brain potentials were amplified by Tektronix Low Level Preamplifiers, Type 122. As the signal-to-noise ratio of ECRs to individual clicks is usually too low for useful measurement, an average was taken of the ECRs to the 50 clicks immediately preceding each signal. This was done by a Mnemotron Computer of Average Transients, which sampled the successive epochs of EEG following $500 \mathrm{msec}$. after each click. An average ECR was thus produced and recorded for measurement by hand on an $\mathrm{X}-\mathrm{Y}$ Plotter. Each $\mathrm{S}$ contributed 16 such averaged ECRs (one associated with each of his 16 signals) from which measures of the amplitude and latency of the individual components were taken and correlated with signal detection performance.

\section{Resulfs}

Figure 1 shows the variation over the $41 / 2-\mathrm{hr}$. periods of the test in (1) performance, in terms of signals heard, and (2) the amplitudes of three components of the ECR: a negative deflexion $\left(n_{1}\right)$ whose peak latency was about 95 msec.; a positive deflexion $\left(p_{2}\right)$, latency about $170 \mathrm{msec}$; a later negative deflexion $\left(\mathrm{n}_{2}\right)$, latency about $265 \mathrm{msec}$. The significance of changes in these parameters during the course of the test was assessed by the Average Spearman Rank Order Correlation Coefficient (Lubin, 1961). They were as follows: performance declined, but the trend was not significant; the amplitude of $\mathrm{P}_{2}$ declined $(p<.05)$, although there was a reversal of this trend from 3 rd to 4 th $1 / 2-h r$; the amplitude of $n_{2}$ increased consistently $(p<.01)$; there was little change in $n_{1}$. Measures were also taken of the peak latency of the three components of the ECR but these showed no significant trends over the $41 / 2-h r$. periods of the test.

The possibility of a relationship between the trends of performance and ECR was examined by comparing the ECRs preceding missed and detected signals, see Table 1. Missed signals were associated with greater amplitude of $n_{2}$ (in 8 out of 8 Ss, $p<.01$ ) and with

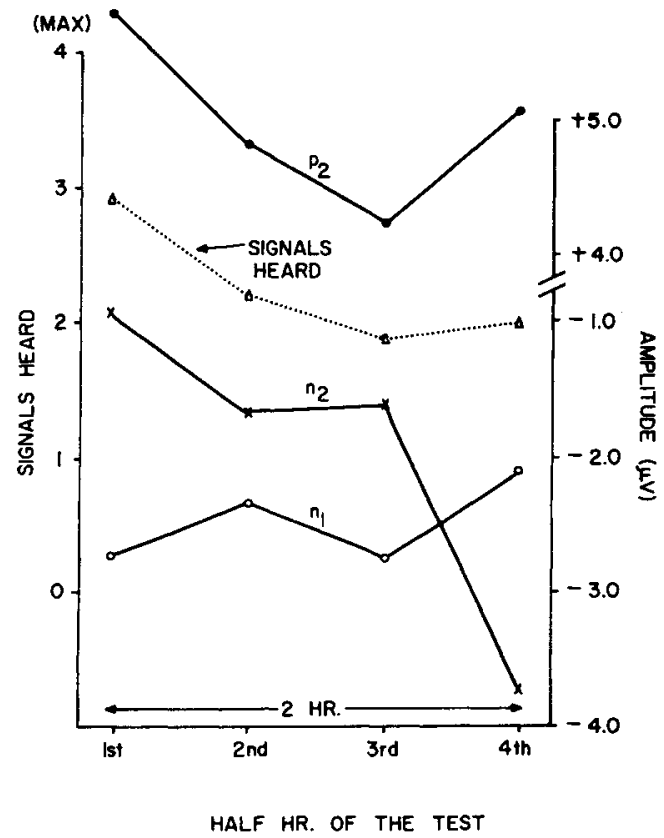

Fig. 1. Amplitude of first negative $\left(n_{1}\right)$, second positive $\left(p_{2}\right)$ and second negative $\left(n_{2}\right)$ components of the evoked cortical response (ECR) and the associated level of signal detection. 
Table 1. Amplitude and latency of the components $n_{1}, p_{2}$ and $n_{2}$ of the ECRs preceding missed and detected signals (* indicates a difference between missed and detected signals which is significant at $p<.02,{ }^{* *}$ indicates the same at $p<.01$ ).

\begin{tabular}{|c|c|c|c|c|c|c|}
\hline & \multicolumn{3}{|c|}{ Amplitude $(\mu v)$} & \multicolumn{3}{|c|}{ Latency (msec) } \\
\hline & ${ }^{n} 1$ & $\mathrm{P}_{2}$ & $n_{2}{ }^{* *}$ & $n_{1}^{*}$ & $P_{2}$ & $\mathrm{n}_{2}$ \\
\hline $\begin{array}{l}\text { Detected } \\
\text { Missed }\end{array}$ & $\begin{array}{l}-2.55 \\
-2.39\end{array}$ & $\begin{array}{l}+5.06 \\
+4.94\end{array}$ & $\begin{array}{l}-1.36 \\
-3.00\end{array}$ & $\begin{array}{r}93.8 \\
102.5 \\
\end{array}$ & $\begin{array}{l}172.0 \\
167.0\end{array}$ & $\begin{array}{l}264.0 \\
268.0\end{array}$ \\
\hline
\end{tabular}

greater latency of $\mathrm{n}_{1}$ (in 7 out of $8 \mathrm{Ss}, \mathrm{p}<.02$ using the Wilcoxon Test (Siegel, 1956)). Since these relationships held even for the unusual Ss who registered more misses during the first than the second half of the test (i.e. showed no vigilance decrement), it follows that these relationships were not due merely to the chance association of unconnected trends in ECR and in performance towards the end of the test. The amplitude of $\mathrm{p}_{2}$ and latency of $\mathrm{n}_{2}$, whose temporal trends also paralleled those of performance, failed to distinguish between missed and detected signals.

The amplitude of $n_{2}$ and the latency of $n_{1}$, then, appear to be reflecting neurophysiological changes associated with the decline in performance during prolonged vigilance. The amplitude of $\mathrm{p}_{2}$, on the other hand, may reflect changes which parallel the decline in vigilance, but which are not related so closely to it. The amplitude of $n_{1}$ and latency of $\mathrm{p}_{2}$ show no clear trends during the course of the test and do not appear to be related to performance. Discussion

These findings constitute one of the few demonstrations of a link between neurophysiological function and vigilance performance. They provide also the first statistically significant demonstration of a relationship between the ECR and the course of the vigilance decrement. If these techniques can be refined and simplified, the ECR might well form an important part of any physiological indicator of the state of alertness of the human operator.

Two behavioral explanations of the vigilance decrement in performance are relevant here. One suggests that it is due to extraneous stimuli distracting the S's attention from those connected with the task (Broadbent, 1958). Another derives from the finding that vigilance decrements are markedly accentuated by loss of sleep (Wilkinson, 1960) and suggests that they are due to a decline in the level of arousal of the S. Evidence on the response of the ECR to various attentional states may help us to assess the nature of the decrement in the present study. It has been reported that the overall amplitude of the ECR declines as attention is diverted from the stimuli which produce it (Garcia-Austt et ai, 1964; Gross et al, 1965; Satterfield, 1965) and increases when a discriminatory response has to be made to the stimuli (Larsson, 1960; Chapman \& Bragdon, 1964). "Overall amplitude" commonly means the distance between the most prominent positive and negative com- ponents of the ECR, which in these studies were $n_{1}$ and $p_{2}$. It would seem reasonable therefore to associate a diversion of attention from the stimuli with a reduction in the amplitudes of these two components, $n_{1}$ and $p_{2}$. A fall in the general level of arousal, on the other hand, as in the transition from waking to sleep (Williams et al, 1962; Weitzman \& Kremen, 1965), is associated mainly with a marked increase in the amplitude of $\mathrm{n}_{2}$ and comparatively little variation in $\mathrm{n}_{1}$ and $\mathrm{p}_{2}$. Now in the present vigilance test it was this latter change, the increase in $\mathrm{n}_{2}$, which was associated with failures of detection. The implication is therefore that it was declining arousal rather than distracted attention which led to lowered performance. This conclusion must be qualified in two ways: (1) While it may be valid in the present vigilance setting it may not hold for others. For example, where the signal frequency is higher the diversion of attention may contribute more than declining arousal to the vigilance decrement (Haider et al, 1964). (2) If changes in the direction of attention are more transitory than those of arousal an ECR measure based on a time-base shorter than the present one (which had to sample 50 stimuli, a period of 1 min. $40 \mathrm{sec}$, before each signal) might be more sensitive to these changes.

\section{References}

Broadbent, D. E. Perception and communication. London: Pergamon Press, 1958. Pp. 108-139.

Chapman, R. M., \& Bragdon, H . R. Evoked responses to numerical and non-numerical visual stimuli while problem solving. Nature, 1964, 203, 1155-1157.

Garcia-Austt, E., Bogacz, J., \& Vanzulli, A. Significance of the photic stimulus on the evoked responses in man. In J. F. Delafresnaye (Ed.), Brain mechanisms and learning. Oxford: Blackwell Scientific Publications, 1961. Pp. 603-621.

Gross, M. M., Begleiter, H., Tobin, M., \& Kissin, B. Auditory evoked response comparison during counting clicks and reading. EEG clin. Neurophysiol, $1965,18,451-454$.

Haider, M., Spong, P., \& Lindsley, D. B. Attention, vigilance, and cortical evoked-potentials in humans. Science, 1964, 145 , 180-182.

Larsson, L. Correlation between the psychological significance of stimuli and the magnitudes of the startle blink and evoked EEG potentials in man. Acta Physiol. Scand., 1960, 48, 276-294.

Mackworth, N. H. Researches on the measurement of human performance. Medical Research Council Report Series No. 268 . 1950, H.M. Stationery Office, London.

Lubin, A. L'utilisation des corrélations par rang pour éprouver une tendance dans un ensemble de moyennes. Bull. du C.E.R.P., $1961,10,433-444$.

Satterfield, J.H. Evoked cortical response enhancement and attention in man. A study of responses to auditory and shock stimuli. EEG clin. Neurophysiol., 1965, 19, 470-475.

Siegel, S. Nonparametric statistics. New York: McGraw-Hill, 1956.

Weitzman, E. D., \& Kremen, H. Auditory evoked responses during different stages of sleep in man. EEG clin. Neurophysiol., $1965,18,65-70$.

Wilkinson, R. T. The effect of lack of sleep on visual watchkeeping. Quart. J. exp. Psychol., 1960, 12, 36-40.

Williams, H. L., Tepas, D. I., \& Morlock, H. C. Evoked responses to clicks and electroencephalographic stages of sleep in man. Science, 1962, 138, 685-686.

\section{Notes}

1. Now at Applied Psychology Research Unit, Cambridge, Engliund.

2. Now at State University College, Plattsburgh, N. Y.

3. Now at University of Oklahoma, School of Medicine. 